\title{
Temperature Dependences of Structural Parameters of PMN in the Region of Diffuse Phase Transition
}

\author{
Alla Lebedinskaya ${ }^{1, *}$, and Angela Rudskaya $^{2}$ \\ ${ }^{1}$ Academy of Architecture and Arts SFU, 39 Budennovskiy Av., Rostov-on-Don, 344002, Russia \\ ${ }^{2}$ Department of Physics SFU, 5, Zorge St., Rostov-on-Don, 344090, Russia
}

\begin{abstract}
In this work, we analyzed the structural parameters of the lead magnoniobate sample in the temperature range from $20^{\circ} \mathrm{C}$ to $450{ }^{\circ} \mathrm{C}$ by Xray structural analysis. It was found that the PMN cubic perovskite cell does not undergo distortions over the entire temperature range under study. In the vicinity of a temperature of $250^{\circ} \mathrm{C}$ in PMN, an abrupt decrease in the coefficient of linear expansion from $1.06 \cdot 10^{-5} \mathrm{~K}^{-1}$ to $0.32 \cdot 10^{-5} \mathrm{~K}^{-1}$, which is possibly associated with a change in the anharmonicity of the potential relief of atoms in the structure, is recorded.
\end{abstract}

\section{Introduction}

Ferroelectrics-relaxors, most of which are perovskite-like compounds with nonisovalent substitution of atoms for equivalent positions $\left(A_{y}^{\prime} A^{\prime \prime}{ }_{1-y}\right)\left(B_{x}^{\prime} B^{\prime \prime}{ }_{1-x}\right) O_{3}$, were first synthesized in the middle of the twentieth century [1-4]. The study of ferroelectrics relaxors is of interest from the point of view of the search for new highly efficient materials for ferroelectric memory devices, including those with optical information recording [5-7].

In a number of ferroelectric materials $\mathrm{Pb}(\mathrm{Mg}, \mathrm{Nb}) \mathrm{O}_{3}, \mathrm{~Pb}(\mathrm{Sc}, \mathrm{Nb}) \mathrm{O}_{3}, \mathrm{~Pb}(\mathrm{In}, \mathrm{Nb}) \mathrm{O}_{3}$, etc. ferroelectric phase transitions occur in a certain temperature range. Such transitions are collectively referred to as «diffuse phase transitions».

The distinctive features of ferroelectric relaxors include: the presence of a wide frequency-dependent maximum of the dielectric constant, significant frequency dispersion in the temperature region below this maximum, and also a large value of the dielectric constant in a wide temperature range [8-14].

In works [11, 15-17] lead magnoniobate $\mathrm{PbMg}_{1 / 3} \mathrm{Nb}_{2 / 3} \mathrm{O}_{3}(\mathrm{PMN})$ is considered as a model for studying the properties of this class of compounds. It is noted that this lead magnoniobate is formed through the pyrochlore phase. Its dielectric constant is high: $\sim 10^{3}$ at room temperature and $\sim 10^{4}$ at the temperature $T_{c}$, and the $\mathrm{E}(\mathrm{T})$ curve has diffuse maxima, which shift towards high temperatures with increasing frequency of the measuring field. Structural studies did not reveal a change in the cubic symmetry of the crystal $[16,18]$.

* Corresponding author: lebed1989@rambler.ru 
At low temperatures, dielectric hysteresis loops are observed, which makes it possible to assert that this compound is a ferroelectric.

It was found that in PMN crystals, when a constant electric field is applied, a transition occurs from a macroscopically non-polar state to a ferroelectric phase. Moreover, if the field is applied along [11], the symmetry is rhombohedral, and along [10], it is assumed to be rhombic $[14,16]$.

Currently, the following reasons for the blurring of the phase transition have been established [1-4, 9, 11]:

1. large-scale heterogeneity of the physical system;

2. fluctuations of physical quantities that characterize the state of the system in the phase transition area;

3. influence of various external and internal fields;

4. surface effects.

Today a huge amount of experimental material has been accumulated and many properties of relaxor ferroelectrics have been studied in detail $[10,11,19,20]$. However, the microscopic nature of the observed phenomena is still ambiguous.

\section{Materials and methods}

\subsection{Fabrication of samples}

For the study, a sample of $\mathrm{PbMg}_{1 / 3} \mathrm{Nb}_{2 / 3} \mathrm{O}_{3}$ was taken. It was prepared by grinding single crystals grown in the laboratory of the Research Institute of Physics of the Southern Federal University. The resulting powder had a grain size of not more than $5 \mu \mathrm{m}$. Then it was pressed into a pellet with a diameter of $10 \mathrm{~mm}$ and a thickness of $2 \mathrm{~mm}$, then annealed in a high-temperature chamber at a temperature of $550^{\circ} \mathrm{C}$ for two hours. Annealing was carried out to remove microdeformations introduced during grinding and pressing of the sample.

\subsection{X-ray structural studies}

X-ray structural studies of the samples were carried out on a DRON-3M X-ray diffractometer $\left(\mathrm{CuK}_{\alpha}\right.$ - radiation) with a GUR-5 goniometer.

The types of crystal structures, their symmetry, and cell parameters were specified.

Lines with $\mathrm{N}=4$ (reflection 200), $\mathrm{N}=5$ (reflection 210), $\mathrm{N}=16$ (reflection 400), $\mathrm{N}=20$ (reflection 420), where $\mathrm{N}=\mathrm{h}^{2}+\mathrm{k}^{2}+\mathrm{l}^{2}$, were chosen as reference. To obtain precision X-ray structural data, a discrete operation mode was used with a detector movement step of $0.05^{\circ}$ in an angle $2 \theta$ and an exposure time at each point of $40 \mathrm{~s}, 100 \mathrm{~s}$, $200 \mathrm{~s}$ respectively for each of the selected diffraction reflections.

The studies were carried out in the temperature range from $450{ }^{\circ} \mathrm{C}$ to $20^{\circ} \mathrm{C}$ with a temperature step of $50{ }^{\circ} \mathrm{C}$.

A high-temperature chamber was used for heating. The temperature in it was maintained by the VRT-2 system. A platinum-platinum-rhodium thermocouple, which is located near the nichrome heater of the chamber, is used to set the work assignment for the VRT-2. The second, chromel-alumel thermocouple is located close to the sample and is designed to measure the temperature near the sample surface.

Computer processing of the experimental data made it possible to find out the position of the maxima of diffraction reflections, their intensities and half-widths.

As a result, the integral intensities of diffraction reflections were calculated at each temperature, the cell parameters were calculated as a function of temperature, and it became possible to trace the distortion of the perovskite cell in the temperature range from $450{ }^{\circ} \mathrm{C}$ to $20^{\circ} \mathrm{C}$. Using the obtained temperature dependences of the half-widths of the diffraction 
maxima, it is possible to estimate the magnitudes of microstrains and the sizes of the coherent scattering regions.

\section{Experimental results and discussion}

The diffraction reflections studied in this work in the entire investigated temperature range were single reflections with a clear splitting at the wavelengths $\mathrm{K}_{\alpha 1}$ and $\mathrm{K}_{\alpha 2}$. This allows us to state that in the temperature range from $20^{\circ} \mathrm{C}$ to $450{ }^{\circ} \mathrm{C}$ the crystal cell of PMN is cubic with the space group of symmetry $\mathrm{Pm} 3 \mathrm{~m}$.

The obtained values of the positions of the diffraction maxima were used to calculate the parameters of the cubic perovskite cell of $\mathrm{PbMg}_{1 / 3} \mathrm{Nb}_{2 / 3} \mathrm{O}_{3}$ at different temperatures. Analysis of the position of the diffraction maximum 420 made it possible to calculate the cell parameter with an absolute error $\Delta \mathrm{a}= \pm 4 \cdot 10^{-4} \AA$ (diffraction angle $\theta_{420} \approx 58^{\circ}$ ). The dependence of the parameter of the cubic cell on temperature is shown in Fig. 1.

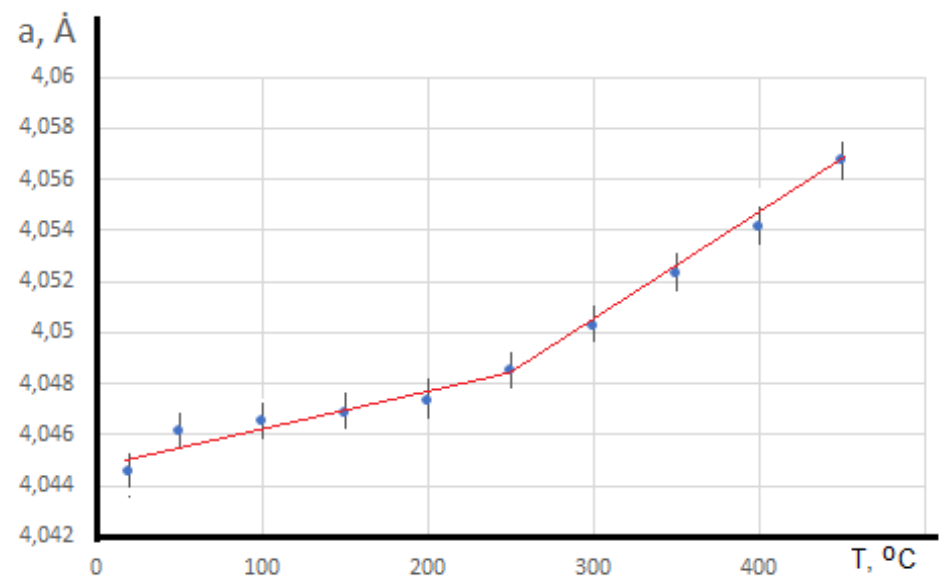

Fig. 1. Temperature dependence of the cubic cell parameter a of lead magnoniobate

As the temperature decreases from $450{ }^{\circ} \mathrm{C}$ to $250{ }^{\circ} \mathrm{C}$, the cubic cell parameter decreases linearly from 4.0566(4) $\AA$ to 4.0484 (4) $\AA$. With a further decrease in temperature, a weak linear decrease in the parameters ak is observed to 4.0450 (4) $\AA$ at $20^{\circ} \mathrm{C}$. As a result, the a (T) dependence shows a break in the vicinity of a temperature of $250{ }^{\circ} \mathrm{C}$. The obtained data were used to calculate the coefficient of linear expansion $\alpha$. In the temperature range from $20^{\circ} \mathrm{C}$ to $250{ }^{\circ} \mathrm{C}$ it is numerically equal to $0.32 \cdot 10^{-5} \mathrm{~K}^{-1}$, and in the temperature range from $250{ }^{\circ} \mathrm{C}$ to $450^{\circ} \mathrm{C}$ the coefficient of linear expansion $\alpha$ is equal to $1.06 \cdot 10^{-5} \mathrm{~K}^{-1}$. A significant change in the coefficient of linear expansion near $250{ }^{\circ} \mathrm{C}$ can indicate a certain rearrangement of the crystal structure at this temperature. It is at these temperatures that the nucleation of spontaneously polarized clusters in the pseudocubic perovskite phase begins $[14,17]$. With decreasing temperature in the region of a diffuse phase transition, their number gradually increases. The nucleation and gradual increase of spontaneously polarized microregions can be the reason for the relatively small value of the coefficient of linear expansion, which is observed at these temperatures.

Further studies of the behavior of the cell parameter at temperatures below room temperature, along with a comparison with the results of electrophysical experiments, may allow a more thorough analysis of the reasons for the observed change in the coefficient of linear expansion. 
The temperature dependences of the half-widths of the studied diffraction reflections are shown in Fig. 2, 3. Reflections of type $h 00$ (200 and 400) and type $h k 0$ (210 and 420) of different orders were chosen as reference.

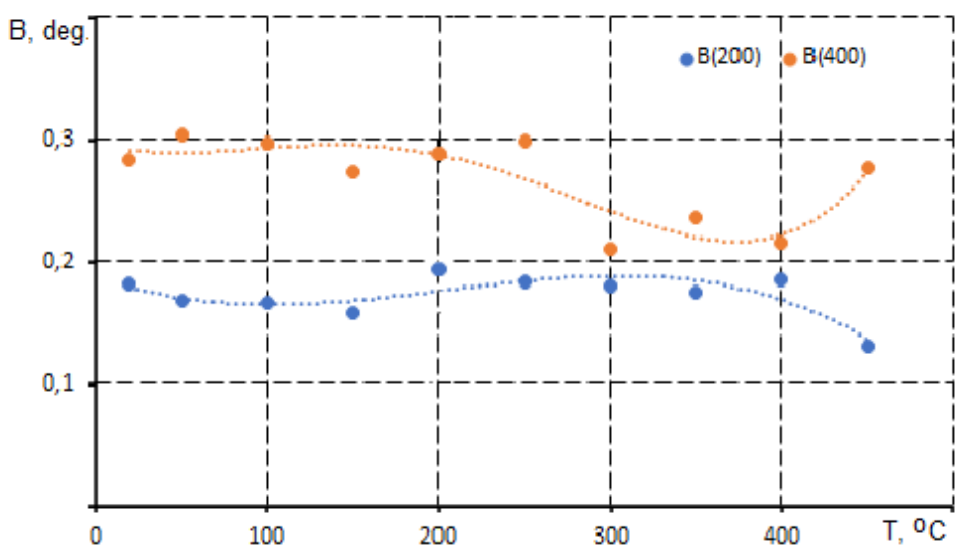

Fig. 2. Dependence of the half-widths of diffraction reflections (200) and (400) from temperature

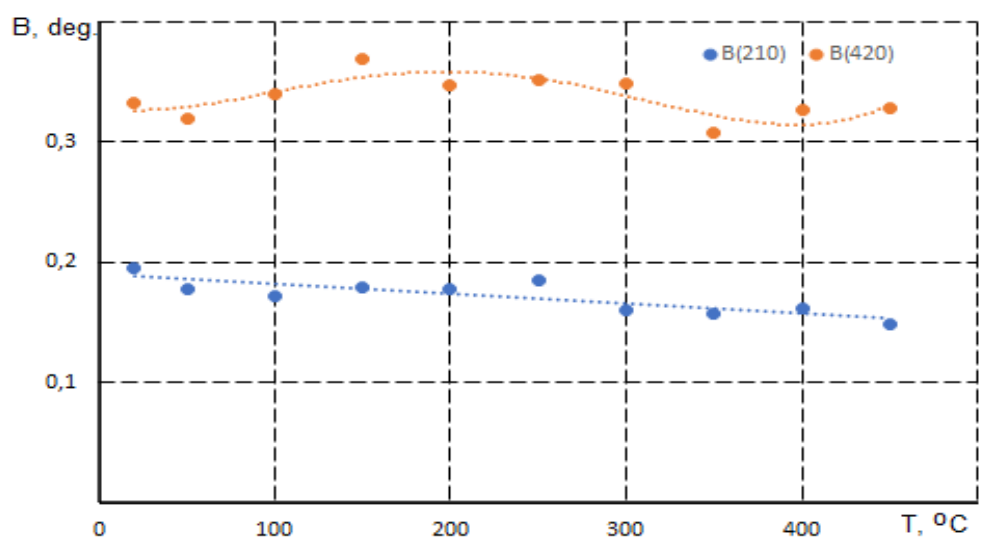

Fig. 3. Dependence of the half-widths of diffraction reflections (210) and (420) from temperature

The plotted dependences of the half-widths in the temperature range from $450{ }^{\circ} \mathrm{C}$ to $20^{\circ} \mathrm{C}$ allow us to note that practically no regularities are observed in the behavior of the half-widths, that is, the half-widths remain almost unchanged within the error within the entire investigated temperature range.

Thus, in the region of the diffuse phase transition in $\mathrm{PbMg}_{1 / 3} \mathrm{Nb}_{2 / 3} \mathrm{O}_{3}$, there is no change in the sizes of the coherent scattering regions and the magnitudes of microstrains, which are uniquely related to the half-widths of the diffraction reflections.

\section{Conclusion}

In this work, the structural parameters of a sample of lead magnoniobate $\mathrm{PbMg}_{1 / 3} \mathrm{Nb}_{2 / 3} \mathrm{O}_{3}$ were analyzed in the temperature range from $20{ }^{\circ} \mathrm{C}$ to $450{ }^{\circ} \mathrm{C}$. It was found that the cubic perovskite cell in PMN does not undergo distortion over the entire investigated temperature range. 
In the vicinity of a temperature of $250{ }^{\circ} \mathrm{C}$ in $\mathrm{PbMg}_{1 / 3} \mathrm{Nb}_{2 / 3} \mathrm{O}_{3}$, the coefficient of linear expansion decreases from $1.06 \cdot 10^{-5} \mathrm{~K}^{-1}$ to $0.32 \cdot 10^{-5} \mathrm{~K}^{-1}$. An abrupt change in the coefficient of linear expansion $\alpha$ can be associated with a change in the anharmonicity of the potential relief of atoms in the structure. In the region of the diffuse phase transition in $\mathrm{PbMg}_{1 / 3} \mathrm{Nb}_{2 / 3} \mathrm{O}_{3}$, the parameters of the substructure (microdeformations and coherent scattering regions) do not change.

The authors are very grateful to professor M. F. Kupriyanov for his constant interest in this work, fruitful discussion of the research results and great contribution to the formation of systematic research directions on this topic.

\section{References}

1. G.A. Smolensky, V.A. Isupov, Tech. Phys. 24(8), pp.1375-1386 (1954)

2. G.A. Smolensky, V.A. Isupov, A.I. Agranovskaya, J.V. Popov, New ferroelectrics of complex composition. In the book "Physics of Dielectrics", Moscow Academy of Sciences of the USSR, pp.339-346 (1960)

3. G.A. Smolensky, V.A. Isupov, A.I. Agranovskaya, J.V. Popov, Ferroelectrics with a diffuse phase transition, Physics of the Solid State, 2, pp. 2906-2918 (1960)

4. V.A. Isupov, Phys. Solid State, 5(1), 187 (1963)

5. S. Pandya, J. Wilbur, J. Kim, R. Gao, A. Dasgupta, C. Dames, L.W. Martin, Pyroelectric energy conversion with large energy and power density in relaxor ferroelectric thin films, Nature Materials, 17(5), pp. 432-438 (2018)

6. S.E. Park, T.R. Shrout, Ultrahigh strain and piezoelectric behavior in relaxor based ferroelectric single crystals, Journal of Applied Physics, 82(4), pp. 1804-1811 (1997)

7. S.E. Park, T.R. Shrout, Relaxor based ferroelectric single crystals for electromechanical actuators, Materials Research Innovations, 1(1), pp. 20-25 (1997)

8. H. Takagi, K. Sakata, T. Takenaka, Electrostrictive properties of $\mathrm{Pb}\left(\mathrm{Mg}_{1 / 3} \mathrm{Nb}_{2 / 3}\right) \mathrm{O}_{3}$ based relaxor ferroelectric ceramics, Japanese Journal of Applied Physics, 32(9), pp. 4280-4283 (1993)

9. A.A. Bokov, Z.-G.YE Dielectric relaxation in relaxor ferroelectrics. Journal of Advanced Dielectrics, 2(2), pp.1241010-1 (2012)

10. G.A. Samara, The relaxational properties of compositionally disordered ABO3 perovskites. J. Phys. Condens. Matter 15, R367 (2003)

11. L.E. Cross, Relaxor ferroelectrics, Ferroelectrics 76, 241 (1987)

12. DelRe, E. Spinozzi, A.J. Agranat, C. Conti, Nat. Photonics, 5, 39 (2011)

13. D. Viehland, S.J. Jang, L.E. Cross, M. Wuttig, J.Appl. Phys., 68(6), 2916 (1990)

14. E.V Colla., S.B. Vakhrushev, E.Yu Koroleva, N.M Okuneva, Physics of the Solid State, 38(7), 2183 (1996)

15. A.Verbaere , Y. Piffard , Z.G. YE, E. Husson, Mat . Res. Bull., 27,pp.1227-1234 (1992)

16. N. Mathan, E. Husson, G. Calvarin, J.R. Gavarri, A. Morell, Structural study of a poled $\mathrm{PbMg}_{1 / 3} \mathrm{Nb}_{2 / 3} \mathrm{O}_{3}$ ceramics at low temperature, Mat.Res.Bull., 26, pp. 11671172(1991)

17. S.B. Vakhrushev, J.-M. Kiat, B. Dkhil, X-ray study of kinetics of field induced transition from the glass-like to the ferroelectric phase in lead magnoniobate, Solid State Commun., 103(8), pp. 477-482 (1997)

18. A R. Lebedinskaya, N G. Kasparova, Features of the structural model of the lowtemperature phase of lead magnesium niobate-relaxor ferroelectric, Advanced Materials, 224, 267(2019) 
19. F. Bai, N. Wang, J. Li, D. Viehland, P. M. Gehring, G. Xu, G. Shirane, X-ray and neutron diffraction investigations of the structural phase transformation sequence under electric field in $0.7 \mathrm{PbMg}_{1 / 3} \mathrm{Nb}_{2 / 3} \mathrm{O}_{3}-0.3 \mathrm{PbTiO}_{3}$ crystal, Journal of Applied Physics, 96(3), 1620 (2004)

20. Z. Liu, C. Wang, N. Zhang, J. Zhuang, J. Zhang, W. Ren \& Z.-G. Ye, Chemical ordering and relaxor properties in a novel solid solution of (1-x) $\mathrm{PbMg}{ }_{1 / 3} \mathrm{Nb}_{2 / 3} \mathrm{O}_{3}$ $x \mathrm{PbCd} d_{1 / 3} \mathrm{Nb}_{2 / 3} \mathrm{O}_{3}$, Ferroelectrics, 553(1), 14 (2019). 